\title{
Analysis of the growth of strike-slip faults using effective medium theory
}

Atilla Aydin, Rock Fracture Project, Department of Geological and Environmental Sciences, Stanford University, Stanford, California, USA

James G. Berryman, Lawrence Berkeley National Laboratory, Earth Science Division, One Cyclotron Rd., MS/90R1116, Berkeley, California, USA

\section{ABSTRACT}

Increases in the dimensions of strike-slip faults including fault length and thickness of fault rock and the surrounding damage zone collectively provide quantitative definition of fault growth and are commonly measured in terms of slip. A vast amount of field data shows that fault dimensions increase in some fashion as the slip across faults increases though these relationships may not be simple. The field observations also indicate that a common mechanism for fault growth in the brittle upper crust is fault lengthening by linkage and coalescence of neighboring fault segments or strands. In addition, the mechanism of fault zone widening is spreading of fault rock via cataclastic deformation into highly fractured inner damage zone. The most important underlying mechanical reason in both cases is prior weakening of the rocks surrounding a fault's core and between neighboring fault segments by fault-related fractures. Using field observations together with effective medium models, this paper attempts to constrain the reduction in the effective elastic properties of rock in terms of the orientation and density of the fault-related brittle fractures. Calculated and extrapolated values of the Young's and shear moduli for idealized fractured rock masses at fault steps and inner damage zones provide insight into the degree of strength degradation as a function of the angle between fracture sets and fracture density and how increasing fracture density may eventually facilitate fault growth via cataclastic deformation of fractured rock masses. 


\section{INTRODUCTION}

Strike-slip faults, similar to other types of faults, typically have complex architectures with numerous segments or strands of various trace lengths separated by steps or relays of various sizes (Fig. 1a). This discontinuous characteristic of strike-slip faults has been reported for simple incipient faults (Segal and Pollard, 1980; 1983; Gamond, 1983; Willemse et al., 1987; Peacock and Sanderson, 1995) as well as for mature crustal scale faults (Aydin and Nur, 1982; Barka and Kadinsky-Cade, 1988; Wesnousky, 1988; Stirling et al., 1996, Kim et al., 2004) and is thought to be pertinent to a number of properties of strike-slip fault systems including their permeability structure (Sibson, 1985; Martel and Peterson, 1991; Aydin, 2000; Odling et al., 2004), the dynamics and size of earthquake ruptures (Aki, 1989; Harris and Day, 1999; Harris et al., 1999; Wesnousky, 2006; Shaw and Dieterich, 2007), the spatial and temporal evolution of earthquakes (Dewey, 1976; Toksöz et al., 1979; Stein et al., 1997), and growth and scaling of faults (de Joussineau and Aydin, 2009; Scholz, 2002).

One of the fault scaling relationships concerns fault length (L) to fault slip or displacement (D). Various studies of mostly normal faults (Watterson, 1986; Walsh and Watterson, 1987; Schlische et al., 1996; Cowie, 1998; Scholz, 2002) concluded that the length-slip relationship has the form, $\mathrm{L}=\mathrm{D}^{\mathrm{n}}$, where $\mathrm{n}$ was proposed to be between 1 and 2 .

Neighboring segments of strike-slip faults are separated by steps (Fig. 1a). It turns out that strike-slip steps have self similar geometry regardless of the sense of stepping and sense of shearing (Aydin and Schultz, 1990; Aydin and Nur, 1982). However, the failure modes and the distribution of the shearing-related structures may be different from one sense of step to another depending on loading, stress perturbations, rhelogy, and the 
geometry of initial pre-faulting discontinuities (Kim et al., 2004; Myers and Aydin 2004; Peacock and Sanderson, 1991; 1995; Burgmann and Pollard, 1994; Gamond, 1983; 1987; Rispoli, 1981).

Data set collected by Wesnousky (1988) from crustal-scale strike-slip faults suggests that the number of steps per kilometer along strike-slip faults decreases as fault slip increases. Although it is difficult to define uncertainty regarding the fault dimensions measured from published geologic and seismologic maps, recent experimental (Otsuki and Dilov, 2005) and site-specific field data from the same tectonic region and lithology and similar resolution (de Joussineau and Aydin, 2009) appear to confirm this trend. It is also interesting to note that larger size of steps is associated with faults having larger maximum slip magnitudes (Aydin and Nur, 1982; de Joussineau and Aydin; 2009).

The fault length-slip and step count per unit length relationships, regardless of their exact form, implies that faults, like other types of geological structures having different senses of displacement discontinuity, start in small length and grow larger in time and space. As faults grow longer, they are able to interact with the neighboring faults at greater distances. Furthermore, it has been shown that faults extend their lengths by linkage and coalescence of smaller segments through fault steps in order to accommodate larger amount of slip (Segall and Pollard, 1983; Martel et al., 1988; Martel, 1990; Peacock, 1991; Peacock and Sanderson, 1995; Cartwright et al., 1995; Dawers and Anders, 1995; Pachell and Evans, 2002; Scholz, 2002; Myers and Aydin, 2004; de Joussineau and Aydin, 2009). It follows that the length-slip plots for faults which grew by linkage and coalescence is not actually continuous but rather have sharp "jumps" coinciding with large increases in lengths at the merger of neighboring segments and 
"flats" corresponding to the time span between the consecutive merger instances, in which fault lengths stay nearly constant while fault slips catch up the limiting length/slip ratio (Cartwright et al., 1995, Cowie, 1998; Gupta and Scholz, 2000)

Another type of fault scaling relationship illuminates how fault zones become wider as they grow (Fig. 1b). Field data (Hull, 1990; Robertson, 1982; Knott et al., 1996) and theoretical considerations (Scholz, 2002) suggest that the width or thickness of faults increases linearly with fault slip. Agosta and Aydin (2006) and de Joussineau and Aydin (2007) proposed that fault rock zones grow or widen perpendicular to their trend at the expense of highly fractured inner damage zone via cataclastic deformation. This widening is also influenced by the width of the steps along faults (Kim et al., 2004; Childs et al., 2008), which are precursors of fault cores.

An important consequence of lengthening of faults by linkage and coalescence is that larger magnitude of slip takes place in merged or composite segments which tend to straighten the overall through-going fault trace with respect to the earlier segmented or discontinuous trace. This process, which appears to be a second order shear localization phenomenon immediately after the fault zone attains the next composite configuration, is referred to as through-going faulting, fault straightening, and fault zone simplification (Cox and Scholz, 1988; Reches and Lockner, 1994; Le Pichon et al., 2001; Scholz, 2002; Ben-Zion and Sammis, 2003).

As this short introductory account indicates, the discontinuous geometry of strikeslip faults, their segmentation, the geometry and scaling of the segments and steps, and their impact on earthquake rupture, fluid flow and mineralization have attracted considerable interest in the literature. However, aside from a number of papers addressing 
the stress state between neighboring faults and the type and orientation of the linkage structure (Segall and Pollard, 1980; Pollard and Segall, 1987; Du and Aydin, 1993, 1995; Crider and Pollard, 1998; and De Bremaecker and Ferris, 2004), very little attention has been paid to quantification of the elastic parameters leading to the growth of the fault dimensions. To this end, there is only a handful of studies of the criteria for the linkage and coalescence of neighboring faults. The first group of these papers includes those dealing with calculation of the critical damage parameters at fault steps in terms of strain invariants (Lyakhovsky and Ben-Zion, 2009; Lyakhovsky et al., 1997). The second category is rather empirical and is based on a field survey of normal faults and subsequent analysis of displacement-segment separation ratio to define those fields with unlinked and linked configurations (Salivo and Benedicto, 2004). There are also a large number of publications dealing with calculating effective moduli of fractured materials (Lockner and Madden, 1991; Sayers and Kachanov, 1991; Berryman and Grechka, 2006; Grechka and Kachanov, 2006; Berryman 2008). However, these do not deal directly with fault growth and the related problems.

In this paper, we present natural and idealized fracture patterns around faults and within fault steps from the Valley of Fire State Park, Nevada, and use effective medium models to investigate how rocks around and between fault segments weaken by faultingrelated fractures and, consequently, how these intensely fractured rock masses may facilitate the growth of fault dimensions. A related paper (Berryman and Aydin, 2009) dealing with the methodology for calculating effective moduli of fractured medium to be submitted to another journal soon. 


\section{Geological background}

For the last two decades, we have been studying the initiation, interaction and growth of brittle, primarily strike-slip faults in the Jurassic Aeolian Aztec Sandstone with excellent exposures in the Valley of Fire State Park, about $60 \mathrm{~km}$ northeast of Las Vegas, Nevada (Fig. 2) (Cakir and Aydin, 1994; Taylor et al, 1999; Flodin et al., 2005; Myers and Aydin, 2004; Flodin and Aydin, 2004; de Joussineau and Aydin, 2007, 2009; de Joussineau et al., 2007). We have documented that these Cenozoic faults (Bohannon, 1983) with both left- and right-lateral offsets ranging from a few $\mathrm{mm}$ to a few $\mathrm{km}$ initiated from a system of joint zones by shearing of the joints, formation of new splay fractures and their subsequent shearing. By mapping of strike-slip faults with increasing magnitude of slip, the mechanism of fault growth was established to be the linkage and coalescence of initially sheared joint zones and of fault segments at progressively greater scales. It was also concluded that the pattern and orientations of these faults within the Valley of Fire and the surrounding area are reminiscence of the large size strike-slip faults in the southeastern Basin and Range province (Cakir et al., 1998).

Aside from the citations above, there is a large body of publications on various aspects of the sandstone deformation in the form of shear bands (Antonellini et al., 1994; Cakir and Aydin, 1994; Flodin et al., 2003), compaction bands and their permeability (Sternlof et al., 2005; Sternlof et al, 2006; Aydin and Ahmadov, 2009), strike-slip fault zone permeability (Jourde et al., 2002; Flodin et al, 2001, 2004, and 2005; Eichhubl et al. 2004; Ahmadov et al., 2007), and petrophysical and failure properties of the major units of the Aztec Sandstone (Taylor et al., 1997; Flodin et al., 2003) in the study area. 


\section{Conceptual models}

Fig. 1a is an idealized diagram illustrating fundamental geometric attributes of strike-slip faults. Along-strike view shows segments with various lengths $\left(1_{1}, 1_{2}, \ldots 1_{n}\right)$, which include the slip vector direction by definition. Hence, identifying segments assures a basis for determining mean and maximum segment lengths. This view also shows discontinuities along the trace length in the form of steps $\left(\mathrm{s}_{1}, \mathrm{~s}_{2}, \ldots \mathrm{s}_{\mathrm{n}-1}\right)$ with overlaps $\left(\mathrm{o}_{1}\right.$, $\mathrm{o}_{2}, \ldots \mathrm{o}_{\mathrm{n}-1)}$ and widths $\left(\mathrm{w}_{1}, \mathrm{w}_{2}, \ldots \mathrm{w}_{\mathrm{n}-1)}\right.$ or separations (Fig. 1a inset). These parameters provide the bases for calculating the number of steps per length, and the size of the steps along a given strike-slip fault.

Down-dip view also includes segments with steps. We will not consider down-dip segmentation and steps because these steps are perpendicular to the slip vector for strikeslip faults and therefore the vertical fault growth in uniform lithologies is relatively easy. In vertically anisotropic lithologies, the problem becomes more complex by the presence of inelastic rocks such as shale, which is also out of the scope of this paper.

Fig.1b shows a detailed view of fault zone architecture with a fault core, made up of fault rock and slip surfaces. Fault rock is the product of fragmentation and cataclasis when a highly fractured rock is disaggregated, fracture-bounded blocks rotate and translate and grains crush. Slip surfaces are through-going structures that accommodate shear displacement along polished and striated surfaces which usually run through, or occur adjacent to, the fault rock. Fault cores are flanked on both sides by a damage zone which includes a complex fracture system of splay joints and sheared splay joints of various generations. We note that, as depicted in the diagram, the distributions of fault rock and damage zone are highly irregular. The diagram in Fig. $1 \mathrm{~b}$ also illustrates the 
notion that one of the major slip surfaces within the fault core may be continuous from one end to the other, which is meant to represent a through-going fault surface (referred to earlier), and accommodates a large portion of the total slip across the fault zone.

Here, we focus on dimensional attributes and growth processes of a network of strike-slip faults exposed in the Aztec Sandstone cropping out in the Valley of Fire Sate Park and its surroundings (Fig. 2). Although the geometric and mechanical properties of the strike-slip faults at this location appear to be similar to those strike-slip faults from different regions (de Joussineau and Aydin, 2009) as summarized in the introduction section of this paper, we restrict our statistical and conceptual models to the cases that we studied in some details at the Valley of Fire State Park for two reasons: One is that the mechanisms of fault initiation and growth are well-known and the precision of measurements is fairly uniform in a wide range of scales. The accuracy of other data, commonly from various geological maps by different authors, is difficult if not impossible to assess and may introduce some artifacts.

Fault segment length, step number and dimensions, and fault width: Data from about 20 well exposed faults in the study area show that the mean segment length increases with the maximum fault offset (de Joussineau and Aydin, 2009) as idealized in Fig. 3a. We here use a simple idealized trend because the exact nature of the relationship is not the focus. Data collected from the same faults also show that the number of steps per unit length $(\mathrm{km})$ decreases as a function of the maximum fault offsets. Stating this result in a simpler way; when " $n$ " number of segments is reduced to "n-1" segments by linkage of the two neighboring segments, then, "n-1" number of steps will be reduced down to " $n-2$ " steps by destruction of one of the steps. 
The damage zone and fault rock widths increase with increasing fault slip (Flodin et al., 2001; 2005; Myers and Aydin, 2004; de Joussineau and Aydin 2007; 2009). These relationships are not locally smooth, but regardless of the actual forms, can be idealized as shown in Figure $3 \mathrm{~b}$. These trends are more meaningful for considering either mean or maximum widths versus maximum slip values. For example, the damage zone widths are controlled primarily by the location, angle and length of the splay fractures (de Joussineau et al., 2007) whose distribution about the fault may be highly nonuniform.

The nature of fracturing at small fault steps can be characterized as first splay fracturing in response to shearing of the echelon joints (Fig. 4a) and then shearing of the $1^{\text {st }}$ generation of splay fractures and formation of a $2^{\text {nd }}$ generation splay fractures that connect the sheared $1^{\text {st }}$ generation splay fractures (Fig. 4b). The intersection angle between the initial echelon sheared joints and the $1^{\text {st }}$ generation splay fractures varies from about $15^{\circ}$ to $85^{\circ}$ with an average value of about $50^{\circ}$ (de Joussineau et al., 2007).

Figure 5 shows the terminal area of a fault zone with $\sim 65 \mathrm{~cm}$ slip. In this regard, it is analogous to an incipient stage of fault development. Similar to the cases shown in Fig. 4 , shearing of the initial joint system resulted in splay fracturing and continued shearing facilitated the formation of multiple sets of sequential splays localizing into discontinuous pockets of high density fractures, and, in places, fragmentation zones. The incipient short slip surfaces go through these pockets of weakened rock at fault steps.

Figures $6 \mathrm{a}$ and $\mathrm{b}$ show a fault of about $14 \mathrm{~m}$ left-lateral slip, which displays several characteristic architectural elements common to all fairly well developed strikeslip faults in the study area: Fault rock, slip surfaces, and damage zone. Fig. 6a shows domains of different deformation zones and of fracture densities, which allow one to see 
a simpler picture of elongated, noncolinear bodies of the fault rock and the areas of high fracture density.

Figures $6 \mathrm{a}$ and $\mathrm{b}$ also show slip surfaces in various orientations and sizes, one of which is continuous from one end of the mapped area to the other going through the elongated bodies of fault rock. There are also short slip surfaces terminating at an acute angle to the rectilinear strings of fault rock (Fig. 6b). We interpret these diagonal short slip surfaces as relics of the initial sheared joints and the high intensity fracture zones, to a large extent, fracture localization between these sheared joints. Then, the fault rock and the associated slip surfaces sub parallel to the fault core represent the architecture of a new progression in fault growth with a through-going fault core and slip surface representing the latest linkage and coalescence structure, for this portion of the fault.

Figures $7 \mathrm{a}$ and $\mathrm{b}$ show photos and details of fractures on one side of the $14 \mathrm{~m}$ fault. The fault core and the inner and outer damage zones are shown in (a). The details of the inner damage zone are shown in (b). Here, several generations of splay fractures are identified based on their abutting relationships and marked by different color codes. The younger ones fill in between the echelon sheared joints of the initial stage (de Joussineau and Aydin, 2007). 7(c) shows a photo and a detailed map of fine- and coursegrained fault rocks and major through-going slip surfaces along a strike-slip fault with about $45 \mathrm{~m}$ left-lateral slip. Some of the earlier fractures within the course-grained fault rock can still be identified (dotted lines). Also important to point out are the triangular pockets of fine-grained fault rock protruding into the damage zone on the left hand side of the fault core, where the fracture intensity appears to be high. The triangular zones happen to be the domains between one of the main slip surfaces and sheared splay 
fractures, which are known to be the location of higher fracture concentrations based on observations at other locations with similar geometry (Flodin and Aydin, 2004).

Figure 8 is a conceptual model displaying linkage and coalescence of fault segments or strands which result in longer segment lengths, reduced number of fault steps, and wider damage zones and fault core with increasing fault slip. In a simple way, the model depicts how strike-slip faults grow via an interrelated series of processes including splay fracturing, shearing of splay fractures, segment linkage, and formation of through-going slip-surfaces in a hierarchical manner. Progressive lengthening of the linked segments, in turn, drives splay fractures to farther distances from the main body of the fault and thus increases the size of potential steps and eventually the widths of fault cores and fault damage zones.

\section{Analysis using effective medium models}

The premise of this study is that a certain degree of high intensity fracturing at fault steps and fault damage zones weakens the rock masses thereby facilitating fault lengthening through linkage and coalescence of neighboring segments and fault zone widening by incorporation of the fractured and fragmented material into the fault rock via a cataclastic process.

Next, we will use effective medium models to investigate the degradation of the strength and reduction of resistance to cataclastic deformation, which presumably pave the way to the setting of through-going faults. Given the complexity of the fractures around faults, the problem is obviously rather difficult and, at this stage, further simplification is desirable for applications to an effective medium theory. We first 
idealize the common fracture patterns in terms of their orientation-intersection angle, length, and density (Fig. 9a). We then study parametrically the effective elastic moduli of such a configuration as a function of fracture density for each idealized fracture pattern defined by the angle between fracture sets in order to assess the degree of degradations in the moduli values as the fracture density increases. The details of the effective medium theory that we shall employ have been recently described by Berryman and Aydin (2009) and is based on the earlier work by Backus (1962), Schoenberg and Muir (1989), and Berryman and Grechka (2006).

Figure 9(a) shows an idealized fracture network which is consistent in principle with the sequential formation of two fracture sets and their ultimate pattern. Here the lengths $(l)$ of the fractures, the density ( $\rho)$ or spacing (s) of the fractures, and angle $\left(\Phi_{\mathrm{F}}\right)$ between the two sets of fractures characterize the pattern in a layer with a thickness, $\mathrm{h}$.

One of the most commonly used fracture density concepts goes back to Bristow (1960). For a set of rectangular flat fractures, which is the most pertinent to physical properties of fractured media such as resistivity, fluid flow, and elasticity is

$$
\rho=n \pi h^{2} l / 4,
$$

where $n=N / V$, with $N$ and $V$ being the number of fractures and the rock volume, respectively, and $\mathrm{h}$ and $l$, are average fracture height and length, respectively. Taking $\mathrm{t}$ as the average fracture thickness (or fracture aperture), the porosity of a system of rectangular flat fractures with an average spacing value, $\mathrm{s}$, is

$$
\phi=\mathrm{t} / \mathrm{s} .
$$

Then, the fracture density is given as

$$
\rho=\pi \phi \mathrm{h} / 4 \mathrm{t} .
$$


Using (2) and (3), we find that the fracture density is proportional to $\mathrm{h} / \mathrm{s}$. Therefore, the fracture density of, for example, 0.78 (or using the approximation in Eq. (3), a rounded number, $\sim 1.0$ ), corresponds to a commonly observed spacing for one set of opening mode fractures distribution in a layer, for which spacing of a single fracture set scales with the layer thickness. For two sets of overlapping fractures systems of equal density (but could be of different distributions) in a single layer, for example, this value approaches to 0.39 or to 0.5 for the approximate case.

\section{Compliance matrix and the corresponding Young's and shear moduli components}

The quasi-static equation of elasticity can be written in the form, when Voigt notation is used (Nye, 1985; Pollard and Fletcher, 2005):

$$
\left(\begin{array}{c}
\epsilon_{11} \\
\epsilon_{22} \\
\epsilon_{12} \\
\epsilon_{33} \\
\epsilon_{32} \\
\epsilon_{31}
\end{array}\right)=\left(\begin{array}{llllll}
S_{11} & S_{12} & S_{16} & S_{13} & S_{14} & S_{15} \\
S_{21} & S_{22} & S_{26} & S_{23} & S_{24} & S_{25} \\
S_{61} & S_{62} & S_{66} & S_{63} & S_{64} & S_{65} \\
S_{31} & S_{32} & S_{36} & S_{33} & S_{34} & S_{35} \\
S_{41} & S_{42} & S_{46} & S_{43} & S_{44} & S_{45} \\
S_{51} & S_{52} & S_{56} & S_{35} & S_{54} & S_{55}
\end{array}\right)\left(\begin{array}{c}
\sigma_{11} \\
\sigma_{22} \\
\sigma_{12} \\
\sigma_{33} \\
\sigma_{32} \\
\sigma_{31}
\end{array}\right)
$$

Where $\varepsilon$ and $\sigma$ are the six independent components of strain and stress, respectively, and $\mathbf{S}$ is the symmetric 6-by-6 compliance matrix. The numbers $1,2,3$ always indicate Cartesian axes (say, $\mathrm{x}, \mathrm{y}, \mathrm{z}$ respectively). Elastic extension in the $\mathrm{x}$ - or 1-direction is denoted by $\varepsilon_{11}$, etc., while a shearing (torsion or twisting) strain around the $\mathrm{x}$ - or 1-axis is 
represented by $\varepsilon_{23}$, etc. Similarly, the normal stress or tension in the x-direction is $\sigma_{11}$, and the shear stress around the $\mathrm{x}$-axis is symbolized by $\sigma_{23}$, etc.

For any system, the compliance matrix, or its inverse, the stiffness matrix, has six eigenvalues. For an isotropic system, five of these eigenvalues are for shearing modes and one is for pure compression/tension mode. Of the five shearing modes, three are the independent torsional or twisting motions and/or the corresponding stresses; for example, in an isotropic system, $\varepsilon_{23}$, couples simply to $\sigma_{23}$, while all the off-diagonal compliances and/or stiffnesses involving subscripts 4, 5, 6 vanish identically. Two other types of shear modes are eigenmodes for an isotropic system; for example, when $\sigma_{22}=-\sigma_{11}$, we have a "push-pull" or "pure shear" mode resulting in the eigen-response $\varepsilon_{22}=-\varepsilon_{11}$ for the strain. For the isotropic case, there are three distinct versions of these pure shear behaviors that give analogous results, but for nonisotropic systems usually only one of these will actually be an eigenmode - the most common example of this behavior being for transversely isotropic systems.

In the presence of a set of fully aligned fractures in an otherwise isotropic elastic medium, the elastic matrix becomes transversely isotropic. The plane of the aligned fractures is the plane of symmetry, and the direction perpendicular to this plane is the axis of symmetry. Elastic behavior strictly within the plane of symmetry (i.e., twodimensional behavior in this plane) remains isotropic, which is the origin of the term "transverse isotropy" - this type of isotropic behavior thus occurring transversely to the axis of symmetry.

When analyzing such systems in three-dimensional space, it is common to choose the axis of symmetry to coincide with one of the spatial axes, $\mathrm{x}, \mathrm{y}$, and $\mathrm{z}$, or 1, 2, and 3 , 
respectively. This choice makes no difference to the final results but makes some difference to the level of difficulty in obtaining those results. In particular, making a good choice of axes can simplify the matrix of elastic coefficients somewhat, so that, for fully aligned fractures, we have a compliance matrix in the Voigt [Nye (1985)] 6x6matrix-form of the elastic tensor notation:

$$
\mathbf{S}=\left(\begin{array}{cccccc}
\frac{1}{E_{11}} & \frac{-\nu_{12}}{E_{11}} & \frac{-\nu_{13}}{E_{33}} & & & \\
\frac{-\nu_{12}}{E_{11}} & \frac{1}{E_{22}} & \frac{-\nu_{23}}{E_{33}} & & & \\
\frac{-\nu_{13}}{E_{33}} & \frac{-\nu_{23}}{E_{33}} & \frac{1}{E_{33}} & & & \\
& & & \frac{1}{G_{44}} & & \\
& & & & \frac{1}{G_{55}} & \\
& & & & \frac{1}{G_{66}}
\end{array}\right) .
$$

Thus, for orthorhombic symmetry, the diagonal components of the matrix; the Young's moduli $\mathrm{E}_{11}, \mathrm{E}_{22}$, and $\mathrm{E}_{33}$ and the shear moduli $\mathrm{G}_{44}, \mathrm{G}_{55}$, and $\mathrm{G}_{66}$ are inversely related to these diagonal components.

In calculating these components of the effective elastic moduli for a medium with Poisson's ratio of 0.4375 appropriate for sandstone, which has two fracture sets (Fig. 9a), we follow an approach based primarily on layer averaging methods of Backus (1962) and Schoenberg and Muir (1989). The details of the mathematical analysis of the effective properties of such a composite system are given in detail by Berryman and Aydin (2009). Basically, two different layers each containing one set of fractures with the same density ( $\rho$ ) but possibly differing distributions, are considered for the effective moduli calculations (Fig. 9b). After constructing one layer with one of the fracture sets, this layer 
is rotated in such a way that the combined fracture system will have the desired angle between the two fracture sets. This is done by rotating each layer plus/minus one half of the angle between the two fracture sets. In this paper, we investigate cases where the angles between the two fracture sets $\left(\Phi_{\mathrm{F}}\right)$ are, $15^{0}, 30^{\circ}, 45^{0}$ and $60^{\circ}$; the most common range of angles for natural fractures considered in this study. The two layers are either stacked up, which we call "sandwich" configuration (Fig. 9b) or are placed side by side, which we call "contiguous" configuration (Fig. 9c). The former is used for averaging in the z- or 3-axis whereas the later is used for averaging along the $\mathrm{x}$ - or 1-axis. Another side by side contiguous configuration similar to that in Figure $9 \mathrm{c}$ is used for averaging along the $y$ - or 2-direction. Both the contiguous and sandwich configurations represent interacting but not intersecting fracture arrays.

Figure 10 shows the plots of the calculated effective moduli; (a) for the Young's moduli, (b) for the shear moduli, and (c) for the quasi-shear moduli for "pure shear" for each of the four different fracture configurations defined by the angle $\Phi_{\mathrm{F}}=15^{0}, 30^{\circ}, 45^{0}$, $60^{\circ}$ and for a range of fracture densities from 0 to 0.2 . The results show that the $E_{11}$ components of the Young's moduli for all four fracture configurations do not change at all (all four lines overlap along the top blue line in Fig. 10a) with increasing fracture density up to 0.2 . This is because $\mathrm{E}_{11}$ corresponds to uniaxial loading in the $\mathrm{x}$ - or 1direction and the changes of the angles and densities of fractures, as seen from this direction edge-on, make no difference on the effective moduli. The $E_{22}$ and $E_{33}$ components show systematic decrease for all configurations as the fracture densities increase. We note that the $\mathrm{E}_{22}$ for the configuration $\Phi_{\mathrm{F}}=60^{\circ}$ and $45^{\circ}$ experiences greater decreases for the range of densities, whereas $E_{33}$ shows greater decreases for 
configurations with smaller intersection angles $\Phi_{\mathrm{F}}=15^{0}$ and $30^{\circ}$. For example, the effective Young's modulus, $\mathrm{E}_{33}$, corresponding to $\Phi_{\mathrm{F}}=15^{0}$ at a fracture density of 0.2 shows about $30 \%$ reduction with respect to the value for no fracture $(\rho=0)$. We note that the plots for $E_{22}$ and $E_{33}$ have segments with different slopes indicating the nonlinear nature of the moduli variations as the density increases. Since the change of slope occurs at the fracture densities for which the calculations were performed, the change would have been smoother if more runs with intermediate fracture density values were performed.

The plots for the shear moduli components for the four fracture configurations are shown in Fig. 10b. They all are nearly linear except one $\left(\mathrm{G}_{44}\right.$-shearing about the 1- or $\mathrm{x}$ axis). $\mathrm{G}_{66}$ and $\mathrm{G}_{55}$ (shearing about the vertical 3- or $\mathrm{z}$-axis and the 2- or y-axis, respectively) get monotonically weaker for the density range used. However, these moduli show the largest decreases for the fracture configurations $60^{\circ}$ and $15^{\circ}$, respectively. The greatest decrease of the shear moduli occur in the $\mathrm{G}_{44}$ and $\mathrm{G}_{55}$ components (shearing about the 1- or x-axis and 2- or y-axis, respectively) corresponding to the fracture configurations with the lowest angle, $\Phi_{\mathrm{F}}=15^{0}$. However, this decrease amounts to about $20 \%$ of the modulus for the no-fracture state. The curves for $\mathrm{G}_{44}$ components have a crossover at a fracture density $\rho$, between 0.1 and 0.15 . This crossover is curious and remains to be investigated further.

Fig. 10c shows the variation in the effective quasi-shear modulus for pure shear $\left(\mathrm{qG}_{\mathrm{p}}\right)$ as being one of the special cases. This parameter shows a smaller variation of about $5 \%$ with respect to the modulus for the no-fracture state for $\Phi_{\mathrm{F}}=60^{0}$ at the highest fracture density (0.2) used in the calculations. 
Extrapolations: One way of obtaining estimates beyond the range of our more certain knowledge is to use an extrapolation technique. One such method is to extrapolate simply by using the same expansion in powers of $\rho$ that we have been using. However, this approach is likely to give misleading results since higher order fracture influence coefficients for higher powers of $\rho$ would come into play.

One such method is to extrapolate simply by using the same expansion in powers of $\rho$ that we have been using. However, this approach is likely to give misleading results since higher order fracture influence coefficients for higher powers of pwould come into play. The ways in which the shear and quasi-shear moduli vary with increasing fracture density for each configuration in our models are nearly linear. This may warrant some extrapolation using the last segment of the curves (for $\rho$ between 0.1 and 0.2 ) to estimate the critical fracture densities corresponding to the vanishing values of shear moduli components with the greatest decrease in magnitude. Hence, $\mathrm{G}_{55}$ and $\mathrm{G}_{44}$ plots for the intersection angle of $15^{0}$ provide 0.9 for the critical density which is the upper bound for cataclastic failure. The qGp for pure shear gives the highest critical fracture density on the order of about 4.1, which implies that the failure will occur earlier due to weakening of the other elastic parameters. Although the Young's moduli curves showing greater decreases $\left(\mathrm{E}_{33}\right)$ appear to be highly nonlinear, again the last linear segments are used to approximate the densities corresponding to the vanishing value of this component. For these cases the critical values of densities are close to each other for each angular configuration being between 0.88 and 1.01. Just to provide a spacing value to which the JSG reader can relate to: These roughly correspond to a single set fracture spacing range of about $4-5 \mathrm{~cm}$ for a $5 \mathrm{~cm}$ thick bed. However it is possible that cataclastic failure may 
occur at spacings lower than that for thinner layers and having the bedding interfaces fail as part of the fragmentation process which has not been considered in our analyses.

\section{Discussion}

The conceptual models depicting increasing mean segment lengths, decreasing number of steps per unit length, and increasing step size as faults grow are straight forward. It is also generally agreed upon that, as faults grow, the damage zone and the fault rock also widen. However, the widening aspect of the fault growth is somewhat contentious. There are various models for the distribution of fault damage zone. These are recently discussed by Childs et al. (2008), de Joussineau and Aydin (2007), Kim et al. (2004), and Shipton and Cowie (2003). The field data on the fault zone width-slip relationship has been questioned in the literature (Evans, 1990). Furthermore, observations of large amount of slip across surprisingly narrow bands (Chester and Chester, 1998) within wide fault zones along some major faults have been used to cast doubts about the existence of a universal fault rock width-slip relationship. However, detailed studies tracking down progressive evolution of brittle faults in well-exposed outcrops including the present study show that bigger faults generally have wider zones of fault rock and related damage (Martel, 1990; Knott et al., 1996, Willemse et al., 1997; Flodin et al., 2001; 2005; Shipton and Cowie, 2003; Myers and Aydin, 2004, Kim et al., 2004; de Joussineau and Aydin, 2007; 2009; de Joussineau et al., 2007). Albeit, the thickness variations are highly heterogeneous along a given fault (Childs, et al., 2008; de Joussineau and Aydin, 2007; Kim et al., 2004) and their distribution may not be as simple and locally smooth as alluded to by the earlier investigators. 
The premise behind this study is that the patterns of fractures at strike-slip steps and inner damage zones adjacent to fault rocks is complicated but can be simplified to represent the local damage fairly well. Due to high density of fractures, the mechanical properties of the rock mass at these locations are so altered that a new paradigm is required to analyze the conditions leading to the growth of faults by linkage of neighboring segments and by enlargement of fault rock into the adjacent inner damage zone. Thus, this premise separates the present study from those using single linkage structure whether in opening, closing, or shearing modes in pristine rock within the context of the LEFM (see for example, Segall and Pollard, 1980; Du and Aydin, 1993, 1995; Crider and Pollard, 1998; and De Bremaecker and Ferris, 2004). In this regard, the underlying reasoning in our approach is similar to that of the damage concept of Lyakhovsky and Ben Zion (2008) if the fracture density is a proxy for the damage parameter in their model. On the other hand, the linkage criteria for the normal fault relays in map view investigated by Salivo and Benedicto (2004) is not quite analogous for the strike-slip configurations considered in our study for the simple reason that the map view of normal faults does not contain the slip vector. However, the displacementsegment separation ratio, which is a measure of the shear strain across fault steps, used by these authors to characterize various stages of fault linkage may be related to the fracture density used in our study for strike-slip steps. It is likely that the fracture density is related to the shear strain across the zone, however, the nature of such a possible relationship between these parameters is not known.

It appears that the underlying mechanical principle for fault growth processes and many of the related scaling relationships is controlled by the stress concentration at fault 
tips and its length dependence. First, for a simple mode-II fracture, the stress components at a point in the regions away from the fracture tips decay as $(\mathrm{a} / \mathrm{r})^{2}$ for $2 \mathrm{D}$ (Pollard and Segall, 1987) and $(\mathrm{a} / \mathrm{r})^{3}$ for 3D (Ben-Zion and Sammis, 2003), where "a" is half fault length and " $r$ " is the radial distance to the center of the fault. Second, fault interaction is an important factor in the final fault geometry of discontinuous strike-slip faults (Aydin and Schultz, 1990). It turns out that the relative locations of the neighboring fracture tips do have a strong impact on echelon mode-II fracture geometry but this influence is moreor-less independent of the sense of echelon steps. The data on the step size and distribution are also consistent with the earlier results in that larger steps are associated with longer fault segments and, presumably, higher slip magnitudes.

Steps or relay ramps between echelon strike-slip faults include various structures (joints, pressure solutions, other faults, and folds) and eventually are cut through by a through-going fault connecting the echelon fault segments. In our study area, the failure structures at steps and around the fault core are generally mode-I fractures formed either under tensile local stresses (Segall and Pollard, 1980) or compressive local stresses (Horii and Nemat-Nasser, 1985). However, shear bands (Aydin et al., 2006; Shipton and Cowie, 2003) are occasionally observed at narrow contractional steps (Davatzes et al., 2003), which are neglected in this study.

Earlier experimental and theoretical studies have proposed buckling (Peng and Johnson, 1972) and bending (Renshaw and Schulson, 2001) of thin and slender rock slabs between a set of fractures as a mechanism for through-going shear fracture formation. It is difficult to identify these mechanisms in the field. As the field data show, most fracture- bounded blocks have diamond shapes due to dihedral intersection angle between 
the fracture sets and may not be favorable either for buckling or bending. Rather, the triangular areas at the intersection of these fractures appear to be most prone to further fracturing and fragmentation. The rotation and drifting of some fracture-bounded rock blocks with respect to the neighboring blocks can be identified in advanced stages of deformation, particularly within slivers preserved within fault cores. However, the relative timing of these rotations and relative motions with respect to the shear zone evolution cannot be determined.

Presence of multiple sets of fractures formed by splaying within fault steps and inner damage zones with intersection angles less than $90^{\circ}$, requires that all but the youngest set of fractures are sheared. We assume that even the sheared fractures have collinear open fractures along their lengths and, therefore, they can be represented as rectangular flat fractures for the purpose of the effective properties calculations. The mean value of the splay angle turns out to be $50^{\circ}$ (de Joussineau et al., 2007) which falls into the range of angles investigated.

The critical fracture densities of about 0.9 to 1.0 correspond to the lowest vanishing values of shear moduli components $\left(\mathrm{G}_{55}\right.$ and $\left.\mathrm{G}_{44}\right)$ for the intersection angle of $15^{0}$ and one of the Young's moduli component $\left(\mathrm{E}_{33}\right)$ for all four intersection angles. This, of course, is the upper bound for cataclastic failure. It is possible that cataclastic failure for most cases may occur at fracture densities lower than that for thinner layers and having the bedding interfaces fail as part of the fragmentation process which has not been considered in our analyses. The quasi shear modulus for pure shear gives the highest critical fracture density on the order of about 4 , which implies that the failure will occur earlier due to weakening of the other elastic parameters. 


\section{Conclusions}

In this paper, we conceptualized fault growth in terms of increasing dimensions of faults with fault slip and provided examples from the same structural and lithological setting. We idealized complex fracture geometries at strike-slip fault steps and inner damage zones in order to use the effective medium models for gaining an insight in the influence of the fractures on the mechanical properties of rocks along and around the faults. Our results indicate that a significant reduction in most components of the Young's, shear, and quasi-shear (for pure shear) moduli of the fractured rock masses should occur as the fracture density increases modestly. The extrapolated values of the Young's and shear moduli for the fracture configuration which resulted in the greatest moduli reduction would suggest an upper bound value for a critical density of $\sim 0.9$ to 1.0 for each set of fractures corresponding to a rough estimate of critical single set fracture spacing value on the order of $4-5 \mathrm{~cm}$ for a bed thickness of $5 \mathrm{~cm}$. This, in turn, sheds some light on possible fracture densities for two sets of fractures leading to linkage and coalescence of neighboring segments and to spread of cataclastic deformation along fault zones into their inner damage zones. Increasing number of fracture sets and slip across, or opening of, bed interfaces may facilitate failure at smaller bed normal fracture densities.

Acknowledgement: The works at the Valley of Fire State Park by many former graduate students and postdocs who studied with AA at Stanford University formed the foundation for establishing the conceptual models in this paper. A partial list of these includes R. Myers, E. Flodin, N. Davatzes, P. Eichhubl, and G. de Joussineau. AA is supported by 
the U. S. DOE Basic Energy Science, Division of Chemical Sciences, Geosciences and Bio-Sciences, Grant \# DE-FG03-94ER14462. Work of JGB performed under auspices of the U. S. DOE by the University of California Lawrence Berkeley National Laboratory under contract no DE-ACO2-05CH11231. AA thanks the Valley of Fire State Park personnel for their support of the field campaigns through many years.

\section{References}

Agosta, F., and Aydin, A., 2006. Architecture and deformation mechanism of a basin bounding normal fault in mesozoic platform carbonates, central Italy. Journal of Structural Geology 28, 2445-2467.

Ahmadov, R., Aydin, A., Karimi-Fard, M., Durlofsky, L., 2007. Permeability upscaling of fault zones in the Aztec Sandstone, Valley of Fire State Park, Nevada with a focus on slip surfaces and slip bands. Hydrogeology Journal, DOI 10.1007/s1004-007-0180-2. Aki, K., 1989. Geometric features of a fault zone related to the nucleation and termination of an earthquake rupture. In: Proceedings of Conference XLV Fault Segmentation and Controls of Rupture Initiation and Termination. U.S. Geological Survey Open File Report 89-315, 1-9.

Antonellini, M., Aydin, A., Pollard, D. D., and D'Onfro, P., 1994. Petrophysical study of faults in sandstones using petrographic Image Analysis and X-ray Computerized Tomography. Pure and Applied Geophysics 143, 181-201.

Aydin, A., 2000. Fractures, faults, and hydrocarbon entrapment, migration and flow. Marine and Petroleum Geology 17, 797-814. 
Aydin, A., and Ahmadov, R., 2009. Bed-parallel compaction bands: Their identification, characterization and implications. Tectonophysics (to be submitted).

Aydin, A., Borja, R. I., and Eichhubl, P., 2006, Geological and Mathematical Framework for failure modes in granular rock. Journal of Structural Geology 28, 83-98.

Aydin, A., and Nur, A., 1982. Evolution of pull-apart basins and their scale independence. Tectonics 1, 91-105.

Aydin, A., and Schultz, R.A., 1990. Effect of mechanical interaction on the development of strike-slip faults with echelon patterns, Journal of Structural Geology 12, 123-129.

Backus. G. E., 1962. Long-wave elastic anisotropy produced by horizontal layering. Journal of Geophysical Research 67, 4427-4440.

Barka, A., and Kadinsky-Cade, K., 1988. Strike-slip fault geometry in Turkey and its influence on earthquake activity. Tectonics 7, 663-684.

Ben-Zion, Y., and Sammis, C.G., 2003. Characterization of fault zones. Pure and Applied Geophysics 160, 677-715, 0033-4553/03/040677-39.

Berryman, J. G., 2008. Elastic and transport properties in polycrystals of cracked grains: Cross-property relations and microstructure. International Journal of Engineering Science $46,500-512$.

Berryman, J. G., and Aydin, A., 2009. Quasi-static analysis of elastic behaviour for some higher density crack systems. International Journal of Numerical and Analytical Methods in Geomechanics (to be submitted).

Berryman, J. G., and Grechka, V., 2006. Random polycrystals of grains containing cracks: Model of quasistatic elastic behavior for fractured systems. Journal of Applied Physics 100, 113527. 
Bohannon, R.G.,1983. Mesozoic and Cenozoic tectonic development of the Muddy, North Muddy, and northern Black Mountains, Clark County, Nevada. In: Miller, D. M, Todd, V. R., and Howard, K. A., (Editors), Tectonic and stratigraphic studies in the eastern Great Basin, Geological Society of America Memoir 157, 125-148.

Bristow, J., 1960. Microcracks and the static and dynamic elastic constants of annealed and heavily cold-worked metals. British Journal of Applied Physics 11, 81-85.

Burgmann, R., and Pollard, D. D., 1994. Strain accommodation about strike-slip fault discontinuities in granitic rock under brittle-to-ductile conditions. Journal of Structural Geology 16, 1655-1674.

Cakir, M., and Aydin, A., 1994. Tectonics and fracture characteristics of the Northern Lake Mead, SE Nevada, Proceedings of the Stanford Rock Fracture Project Workshop, Field guide book.

Cakir, M., Aydin, A., and Campagna, D. J., 1998. Deformation pattern around conjoining strike-slip faults systems in the Basin and Range, southeast Nevada: The role of strike-slip faulting in basin formation and inversion. Tectonics 17, 344-359.

Cartwright, J. A., Trudgill, B. D., and Mansfield, C. S., 1995. Fault growth by segment linkage: an explanation for scatter in maximum displacement and trace length data from the Canyonlands Grabens of SE Utah. Journal of Structural Geology 17, 13191326.

Chester, F. M., and Chester, J. S., 1998. Ultracataclasite structure and friction processes of the San Andreas Fault. Tectonophysics 295, 199-221. 
Childs, C., Manzocchi, T., Walsh, J. J., Bonson, C. G., Nicol, A., and Schopfer, M. P. J., 2008. A geometric model of fault zone and fault rock thickness variations. Journal of Structural Geology, doi:10.1016/j.jsg.2008.08.009.

Cowie, P. A., 1998. Normal fault growth in three dimensions in continental and oceanic crust, in Faulting and Magmatism in Mid-Ocean Ridges. Geophysical Monograph Series $106,325-349$.

Cowie, P.A., and Scholz, C.H., 1992. Displacement-length scaling relationship for faults: data synthesis and discussion. Journal of Structural Geology 14, 1149-1156.

Cox, S. J. D., and Scholz, C. H., 1988. Rupture initiation in shear fracture of rocks: An experimental study. Journal of Geophysical Research 93, 3307-3320.

Crider, J.G., and Pollard, D.D., 1998. Fault linkage: three-dimensional mechanical interaction between echelon normal faults. Journal of Geophysical Research 103, 24373 24391.

Davatzes, N.C., Aydin, A., and Eichhubl, P., 2003. Overprinting Faulting Mechanisms During the Development of Multiple Fault Sets in Sandstone, Chimney Rock, Utah. Tectonophysics 363, 1-18.

Dawers, N. H., and Anders, M. H., 1995. Displacement-length scaling and fault linkage. Journal of Structural Geology 17, 607-614.

Dawers, N. H., Anders, M. H., and Scholz, C. H., 1993. Growth of normal faults: Displacement-length scaling. Geology 21, 1107-1110.

De Bremaecker, J.-Cl. ; Ferris, M. C., 2004. Numerical models of shear fracture propagation. Engineering Fracture Mechanics 71, 2161-2178. 
de Joussineau, G., and Aydin, A., 2009. Segmentation along strike-slip faults and their self-similar architecture. Pure and Applied Geophysics (submitted).

de Joussineau, G., and Aydin, A., 2007. The evolution of the damage zone with fault growth and its multiscale characterization. Journal of Geophysical Research 112, B12401, doi:10.1029/2006JB004711.

de Joussineau, G., Mutlu, O., Aydin, A., and Pollard, D.D., 2007. Characterization of strike-slip fault-splay relationships in sandstone. Journal of Structural Geology 29, 18311842.

Dewey, J. W., 1976. Seismicity of Northern Anatolia. Bulletin Seismological Society of America $66,843-868$.

Du, Y., and Aydin, A., 1995. Shear fracture patterns and connectivity at geometric complexities along strike-slip faults. Journal of Geophysical Research 100, 18093-18102.

Du, Y., and Aydin, A., 1993. The maximum distortional strain energy density criterion for shear fracture propagation with applications to the growth paths of en echelon faults. Geophysical Research Letters 20, 1091-1094.

Eichhubl, P., Taylor, W. L., Pollard, D.D., and Aydin, A., 2004. Paleo-fluid flow and deformation in the Aztec Sandstone at the Valley of Fire, Nevada-Evidence for the coupling of hydrogeologic, diagenetic and tectonic processes. Geological Society of America Bulletin 116, 1120-1136.

Evans, J. P., 1990. Thickness-displacement relationships for fault zones. Journal of Structural Geology 12, 1061-1065. 
Flodin, E. A. and Aydin, A., 2004. Evolution of a strike-slip fault network, Valley of Fire, southern Nevada. Geological Society of America Bulletin 116, 42-59, DOI 10.1130/B25282.1.

Flodin, E. A., Durlofsky, L. J. and Aydin, A., 2004. Upscaled models of flow and transport in faulted sandstone: Boundary condition effects and explicit fracture modeling. Petroleum Geoscience 10, 173-181.

Flodin, E., Aydin, A., Durlofsky, L. J., and Yeten, B., 2001. Representation of Fault Zone Permeability in Reservoir Flow Models. Society of Petroleum Engineers paper \# 71617, $1-10$.

Flodin, E. A., Gerdes, M., Aydin, A., and Wiggins, W. D., 2005. Petrophysical properties of cataclastic fault rock in sandstone. In: Sorkhabi, R., and Tsuji, Y., (editors), Faults, fluid flow, and petroleum traps. American Association of Petroleum Geologists Memoir $85,197-227$.

Flodin, E; Prasad, M; Aydin, A., 2003. Petrophysical constraints on deformation styles in Aztec sandstone, Southern Nevada, USA. Pure and Applied Geophysics 160, 1589-1610. Gamond, J. F., 1983. Displacement features associated with fault zones: a comparison between observed examples and experimental models. Journal of Structural Geology 5, $33-45$.

Gamond, J. F., 1987. Bridging structures as sense of displacement criteria in brittle fault zones. Journal of Structural Geology 9, 609-620.

Grechka, V., and Kachanov, M., 2006. Seismic characterization of multiple fracture sets: Does orthotropy suffice? Geophysics 71, D93-D105. 
Gupta, A., and Scholz, C.H., 2000. A model for fault interaction based on observations and theory. Journal of Structural Geology 22, 865-879.

Harris, R. A., and Day, S. M., 1999. Dynamic 3D simulation of earthquakes on en echelon faults. Geophysical Research Letters 26, 2089-2092.

Harris, R. A., Archuleta, R. J., and Day, S. M., 1999. Fault steps and the dynamic rupture process: 2-d simulation of a spontaneously propagating shear fractures. Geophysical Research Letters 18, 893-896.

Horii, H., and Nemat-Nasser, S., 1985. Compression-induced microcrack growth in brittle solids: axial splitting and shear fracture. Journal of Geophysical Research 90, $3105-3125$.

Hull, J., 1989. Thickness-displacement relationships for deformation zones. Journal of Structural Geology 10, 431-435.

Jourde, H., Flodin, E.A., Aydin, A., and Durlofsky, L.J., 2002. Computing permeability of fault zones in eolian sandstone from outcrops measurements. American Association of Petroleum Geologists Bulletin 86, 1187-1200.

Kim, Y., Peacock, D. C. P., and Sanderson, D. J., 2004. Fault damage zones. Journal of Structural Geology 26, 503-517.

Knott, S. D., Beach, A., Brockbank, P. J., Brown, J. L., McCallum, J. E., and Welbon, A. I., 1996. Spatial and mechanical controls on normal fault population. Journal of Structural G eology 18, 359-372.

Le Pichon, X., Şengör, A. M. C., Demirbağ, E., Rangin, C., İmren, C., Armijo, R., Görür, N., Çağatay, N., Mercier de Lepinay, B., Meyer, B., Saatçilar, R., and Tok, B., 2001. The active Main Marmara Fault. Earth and Planetary Sciences Letters 192, 595-616. 
Lockner, D. A., and Madden, T. R., 1991. A multiple-crack model of brittle fracture 1. Non-time-dependent simulations. Journal of Geophysical Research 96, 19,623-19,642. Lyakhovsky, V., Ben-Zion, Y., 2009. Evolving fault zone structures in a damage rheology model. Earth and Planetary Sci. Letters (submitted).

Lyakhovsky, V., Ben-Zion, Y., Agnon, A., 1997. Distributed damage, faulting, and friction. Journal of Geophysical Research102, 27,635-27,649.

Martel, S. J., 1990. Formation of compound strike-slip fault zones, Mount Abbot quadrangle, California. Journal of Structural Geology. 12:869-882.

Martel, S. J., and J. E. Peterson, Jr. 1991. Interdisciplinary characterization of fracture systems at the US/BK site, Grimsel Laboratory, Switzerland. International Journal of Rock Mechanics and Mining Science and Geomechanical Abstracts 28, 259-323.

Martel, S. J., Pollard, D. D., and Segall, P., 1988. Development of simple strike-slip fault zones in granitic rock, Mount Abbot quadrangle, Sierra Nevada, California. Geological Society of America Bulletin. 99, 1451-1465.

Myers, R. (1999), Structure and hydraulics of brittle faults in sandstone, Ph.D. thesis, Stanford University.

Myers, R., and Aydin, A., 2004. The evolution of faults formed by shearing across joint zones in sandstone. Journal of Structural Geology 26, 947-966.

Nye, J. F.1985. Physical properties of crystals: Their representation by tensors and matrices. Oxford Science Publications.

Odling, N. E, Harris, S. D., and Knipe, R. J., 2004. Permeability scaling properties of fault damage zones in siliclastic rocks. Journal of Structural Geology 26, 1727-1747. 
Otsuki, K., and Dilov, T.,2005. Evolution of self-similar geometry of experimental fault zones; implications for seismic nucleation and earthquake size. Journal of Geophysical Research 110, B03303, doi:10.1029/2004JB003359.

Pachell, M.A., and Evans, J.P., 2002. Growth, linkage, and termination processes of a 10km-long strike-slip fault in jointed granite: the Gemini fault zone, Sierra Nevada, California. Journal of Structural Geology 24, 1903-1924.

Peacock, D. C. P., and Sanderson, D. J., 1995, Strike-slip relay ramps. Journal of Structural Geology 17, 1351-1360.

Peacock, D. C. P., and Sanderson, D. J., 1991. Displacement, segment linkage and relay ramps in normal fault zones. Journal of Structural Geology 13, 721-733.

Peng, S., and Johnson, A. M., 1972. Crack growth and faulting in cylindrical specimens of Chelmsford Granite. International Journal of Rock Mechanics, Mineral Sciences and Geomechanics Abstracts 9, 37-86.

Pollard, D. D., and Fletcher, R. C., 2005. Fundamentals of Structural Geology, Cambridge University Press, Cambridge, UK, 500 p.

Pollard, D. D., and Segall, P., 1987. Theoretical displacements and stresses near fractures in rock: with applications to faults, joints, veins, dikes, and solution surfaces. In:

Atkinson, B., K. (ed), Fracture mechanics of rock, Academic Press, London, UK, 277349.

Reches, Z., and Lockner, D.A., 1994. Nucleation and growth of faults in brittle rocks. Journal of Geophysical Research 99, 18159-18173.

Renshaw, C. E., and Schulson, E. M., 2001. Universal behaviour in compressive failure of brittle materials. Nature 412, 897-899. 
Rispoli, R., 1981. Stress fields about strike-slip faults inferred from stylolites and tension gashes. Tectonophysics 75, 729-736.

Robertson, E. C., 1963. Relationship of fault displacement to gouge and breccia thickness. Mineral Engineering Transactions, American Institute of Mining Engineering $35,1426-1432$.

Salivo, R., and Benedicto, A., 2004. A linkage criterion for segmented normal faults. Journal of Structural Geology 26, 2251-2267.

Sayers, C. M., and Kachanov, M., 1991. A simple technique for finding effective elastic constants of cracked solids for arbitrary crack orientation statistics. International Journal of Solids and Structures 27, 671-680.

Schlische, R.W., Young, S. S., Ackermann, R. V. and Gupta, A., 1996. Geometry and scaling relations of a population of very small rift-related normal faults. Geology $24,683-$ 686.

Schoenberg, M., and Muir, F. A., 1989. A calculus for finely layered anisotropic media. Geophysics 54, 581-489.

Scholz, C. H., 2002. The mechanics of earthquakes and faulting. Cambridge University Press ( $2^{\text {nd }}$ edition), Cambridge, UK, 471p.

Segall, P., and Pollard, D. D., 1980. Mechanics of discontinuous faults. Journal of Geophysical Research 85, 4337-4350.

Segall, P., Pollard, D. D., 1983. Nucleation and growth of strike slip faults in granite. Journal of Geophysical Research 88, 555-568.

Shaw, B. E., and Dieterich, J. H., 2007. Probabilities for jumping fault segment stepovers. Geophysical Research Letters 34, L01307, doi:10.1029/2006GL027980. 
Shipton, Z. K., and Cowie, P. A., 2003. A conceptual model for the origin of fault damage zone structures in high-porosity sandstone. Journal of Structural Geology, 25, 333-344.

Sibson, R. H., 1986. Structural permeability of fluid-driven fault-fracture meshes. Journal of Structural Geology 18, 1031-1042.

Sibson, R. H., 1985. Stopping of earthquake ruptures at dilational fault jogs. Nature 316, $248-251$.

Stein, R. S., Barka, A. A. and Dieterich, J. H., 1997. Progressive failure on the North Anatolian fault since 1939 by earthquake stress triggering. Geophysical Journal Interternational 128, 594604.

Sternlof, K. R., Karimi-Fard, M., Pollard, D. D., and Durlofsky, L. J., 2006. Flow and transport effects of compaction bands in sandstone at scales relevant to aquifer and reservoir management. Water Resources Research 42, W07425, doi:10.1029/2005WR004664.

Sternlof, K. R., Rudnicki, J. W., and Pollard, D. D., 2005. Anticrack inclusion model for compaction bands in sandstone. Journal of Geophysical Research. 110, 1-16, B11403, doi:10.1029/2005JB003764

Stirling, M. W., Wesnousky, S. G., and Shimazaki, K., 1996. Fault trace complexity, cumulative slip, and the shape of the magnitude-frequency distribution for strike-slip faults: a global survey. Geophysical Journal International 124, 833-868.

Taylor, W. L., Myers, R., and Aydin, A., 1997. Geology of the Valley of Fire Sate Park, Southeastern Nevada, Proceedings of the Stanford Rock Fracture Project Field Workshop. 
Taylor, W. L., Pollard, D. D., and Aydin, A., 1999. Fluid flow in discrete joint sets: Field observations and numerical simulations. Journal of Geophysical Research 104, 2898329006.

Toksöz, N., Shakal, A. F., and Michael, A. J., 1979. Space-time migration of earthquakes along the North Anatolian fault zone and seismic gap. Pure and Applied Geophysics 117, 1258-1270. Walsh, J. J., Watterson, J., 1987. Distribution of cumulative displacement and seismic slip on a single normal fault surface. Journal of Structural Geology 9, 1039-1046.

Watterson, J., 1986. Fault dimensions, displacement and growth. Pure and Applied Geophysics $124,365-373$.

Wesnousky, S. G., 1988. Seismological and structural evolution of strike-slip faults. Nature 335, 340-342.

Wesnousky, S. G., 2006. Predicting the endpoints of earthquake ruptures. Nature 444, $358-360$.

Willemse, E. J. M., Peacock, D. C. P., Aydin, A., 1997. Nucleation and growth of strikeslip faults in limestones from Somerset, U. K. Journal of Structural Geology 19, 14611477. 


\section{Figure captions:}

Fig. 1 Idealized diagrams showing: (a) segmentation along strike-slip faults and their segment lengths, heights and step numbers. Overlaps (or step lengths) and step widths (or fault separations) are also shown in inset. (b) Internal architecture of a strike slip fault showing fault core, which includes fault rock and slip surfaces, and the surrounding damage zone.

Fig. 2. Location and generalized map of Cenozoic strike-slip faults in the Valley of Fire region of southern Nevada. Heavy lines are faults. Arrows indicate predominant sense of slip. LMFS = Lake Mead Fault System, LVVSZ = Las Vegas Valley Shear Zone. Rectangle marks the location of the Valley of Fire State Park.

Fig. 3. Idealized diagrams summarizing general trends of (a) mean segment length and number of steps per $\mathrm{km}$, and (b) mean fault rock and mean damage zones widths as the maximum fault slip increases.

Fig. 4. (a) Incipient right-lateral shearing $(\sim 2 \mathrm{~cm})$ of a series of echelon joints with right steps. Splay fractures at high angle to the sheared joints are localized near the tips of the segments at the steps. (b) Two sets of splay fractures at and around a right step along a strike-slip fault with about $80 \mathrm{~cm}$ right-lateral slip. The two sets have a range of intersection angles from $30^{\circ}$ to $60^{\circ}$. 
Fig. 5. Detailed map of the end of a small shear zone of about $65 \mathrm{~cm}$ right-lateral slip showing a set of slightly sheared and highly overlapped echelon joints with many splay joints at high angle to the sheared joints. Gray shading marks narrow pockets of fragmentation and thick lines show incipient through-going slip surfaces orientated at a small angle to the sheared initial echelon joints. Interpreted by AA from a map by $\mathrm{N}$. Davatzes (unpublished).

Fig. 6. (a and b). Detailed maps of a strike-slip fault with about $14 \mathrm{~m}$ left-lateral slip. (b) shows the orientations, lengths, and intersections of damage zone fractures (splay joints and sheared splay joints) around the fault core (Myers and Aydin, 2004) whereas (a) shows a new reinterpreted version of the same fault architecture in which noncolinear pockets of fault rocks and highly fractured domains of occasionally fragmented damage zone are delineated in the field. One through-going slip surface (thick solid line) and several short slip surfaces (dotted lines) diagonal to the through-going slip surface are highlighted. The geometry and distribution of many of short diagonal slip surfaces resemble the initial echelon sheared joints observed along faults with smaller slip in the area. Mapped by N. Davatzes (unpublished) and revised by AA.

Fig. 7. Damage zone characteristics around the strike-slip fault with $\sim 14 \mathrm{~m}$ left-lateral slip. (a) Two fractured domains were distinguished: The inner damage zone of high fracture density right next to the fault core; and the outer damage zone of significantly lower fracture density. (b) A detailed map of the inner damage zone shows that several generations of splay fractures (marked by different color codes) fill in between the 
echelon sheared joints of the initial stage. (a and b from de Joussineau and Aydin, 2007). (c) Detail map showing fine- and course-grained fault rock and major through-going slip surfaces along a left-lateral fault with about $45 \mathrm{~m}$ left-lateral slip. Some of the earlier fractures within the course-grained fault rock can still be identified (dotted lines). Also important to point out triangular pockets of fine-grained fault rock protruding into the damage zone in some locations on the left hand side of the fault core, where the fracture intensity is the highest.

Fig. 8. Conceptual model showing linkage and coalescence of fault segments or strands which result in longer segment lengths, reduced number of fault steps, larger step sizes, and wider damage zones and fault rock zones with increasing fault slip. (From de Joussineau and Aydin, 2007).

Fig. 9. (a). A simplified and idealized fracture pattern at fault steps and within inner damage zones. The pattern is defined by the angle $\left(\Phi_{\mathrm{F}}\right)$ between the two fracture sets and lengths (l) and density ( $\rho$ ) of the fracture systems. Fracture density is proportional to the ratio of layer thickness (h) to average spacing (s). (b and c) Block diagrams showing the procedure to represent layers with each fracture set and the configurations of the layers for averaging the effective properties in $\mathrm{z}$ - and $\mathrm{x}$-directions or 3-and 1-directions, respectively. The block diagrams represent stacking up layers vertically in z-direction (bsandwich configuration) and arranging the layers side by side in $\mathrm{x}$-direction (ccontiguous configuration). 
Fig. 10. Plots showing the variation in elastic moduli of rocks with prescribed fracture patterns (defined by the angle, $\Phi_{\mathrm{F}}$, between two fracture sets as $15^{\circ}, 30^{\circ}, 45^{\circ}$ and $60^{\circ}$ ) and a range of fracture densities ( $\rho$ from 0.05 to 0.2). (a) The three components of the Young's moduli $\left(\mathrm{E}_{11}, \mathrm{E}_{22}\right.$, and $\left.\mathrm{E}_{33}\right)$ with increasing fracture density. The nearly horizontal solid blue line near the top represents all four $\mathrm{E}_{11}$ plots for all four angles between the fracture sets (the lines just overlap). (b) The three components of the shear moduli $\left(\mathrm{G}_{44}\right.$, $\mathrm{G}_{55}$, and $\mathrm{G}_{66}$ ) for the four angles with increasing fracture density ( $\rho$ ). (c) The quasi-shear moduli for pure shear for the same four angular configurations. This moduli show the least decrease in magnitude with respect to that for no-fracture state. 
Aydin and Berryman fig. 1
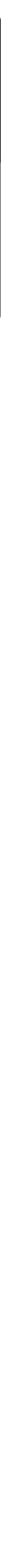

fig. 1 
Aydin and Berryman fig. 2

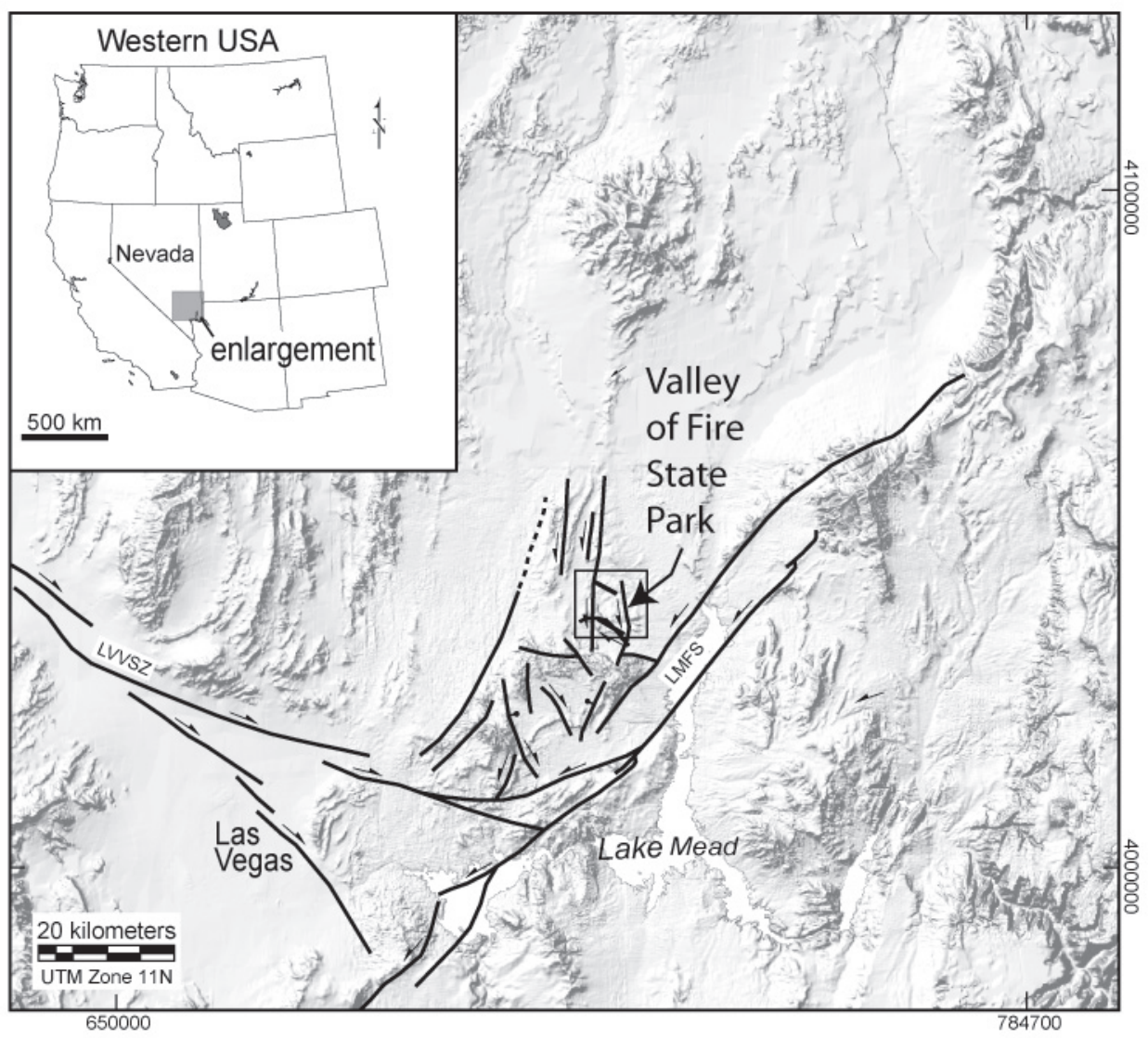


Aydin and Berryman fig. 3

(a)

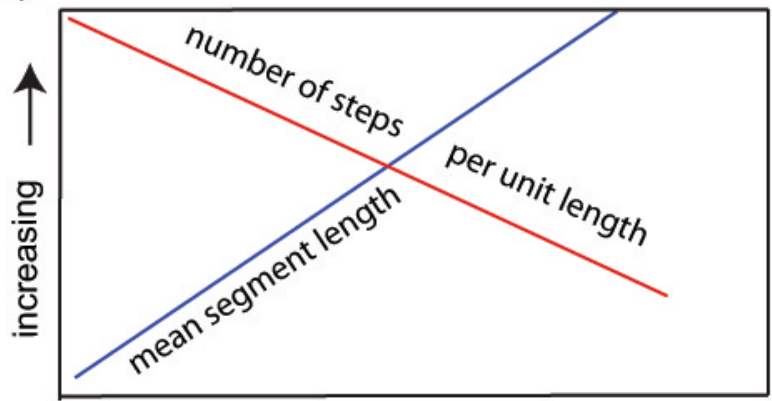

maximum fault offset (increasing)

(b)

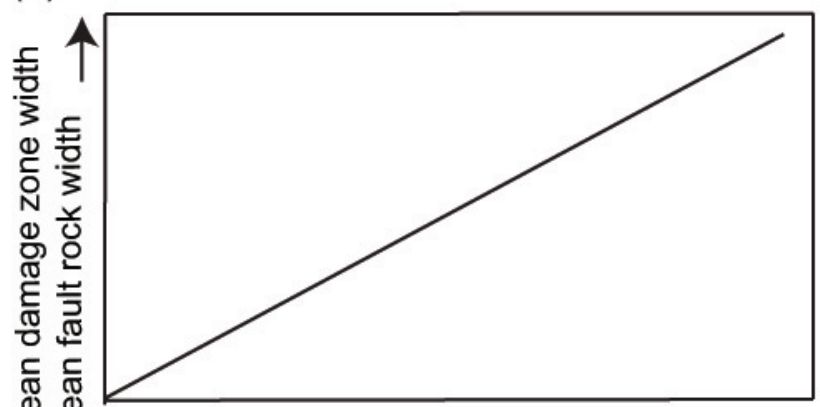

$\sum \stackrel{\infty}{\Sigma}$ maximum fault offset (increasing) $\longrightarrow$ 


\section{Aydin and Berryman fig. 5}

$1 \backslash$ sheared joints

splay joints

through-going slip surfaces

fragmented pockets

$50 \mathrm{~cm}$

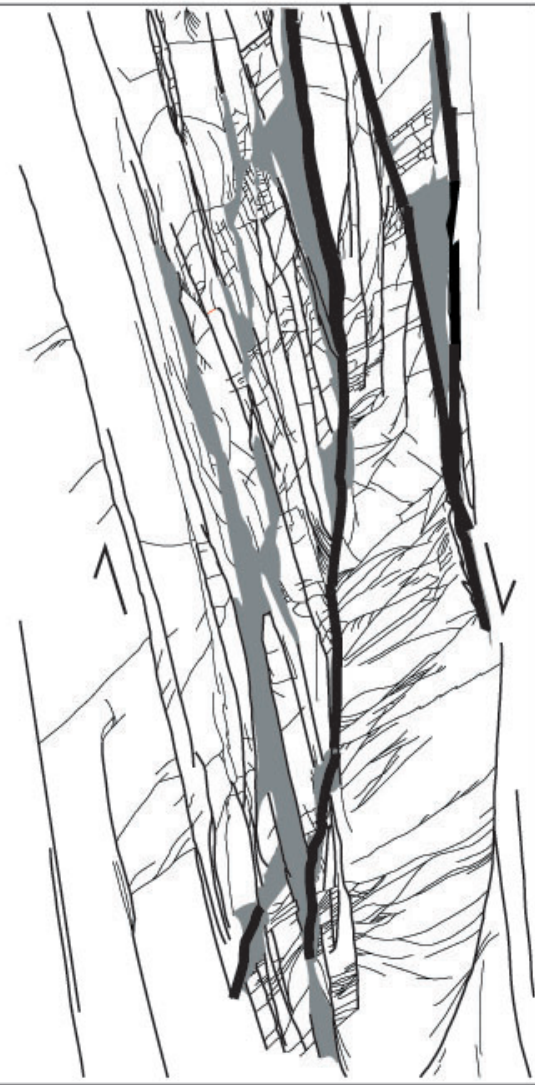




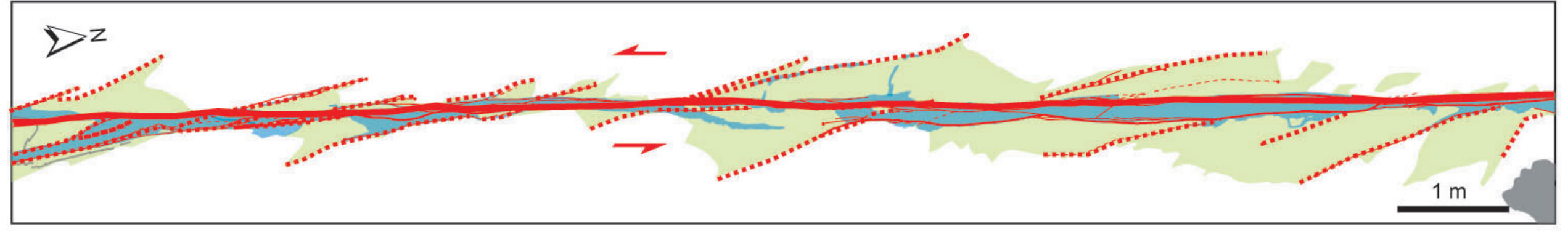

.. Slip surfaces (thick when through-going, dashed discontinuous diagonal)

\section{(b)}

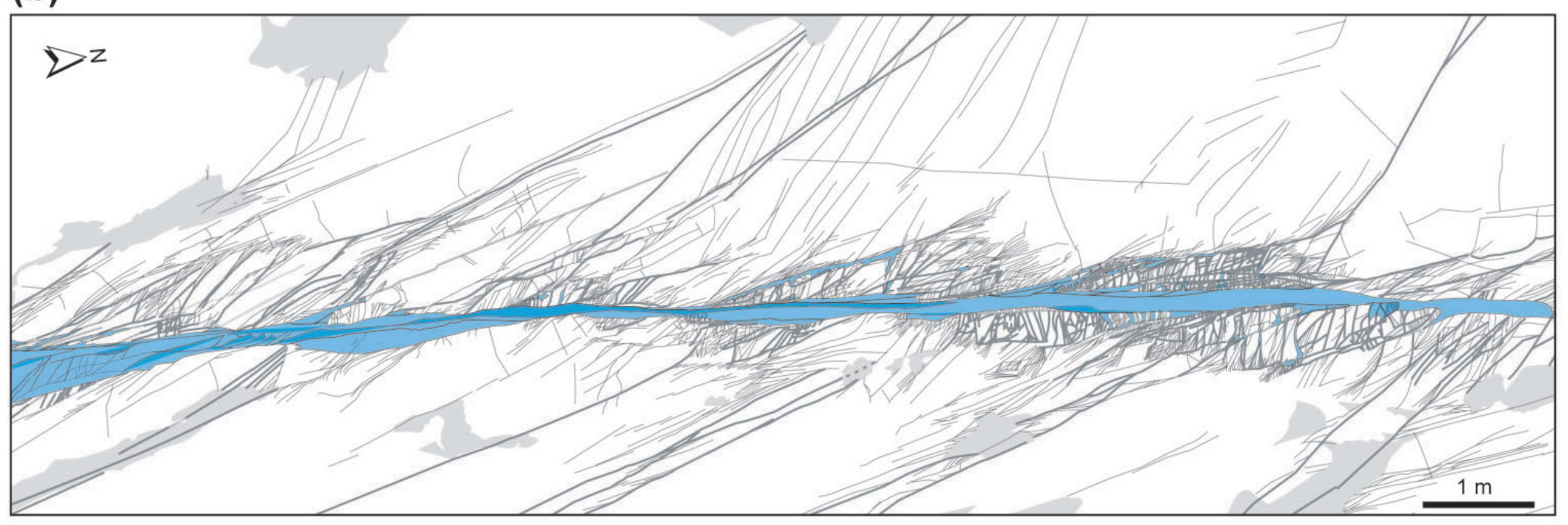




\section{Aydin and Berryman fig. 7}

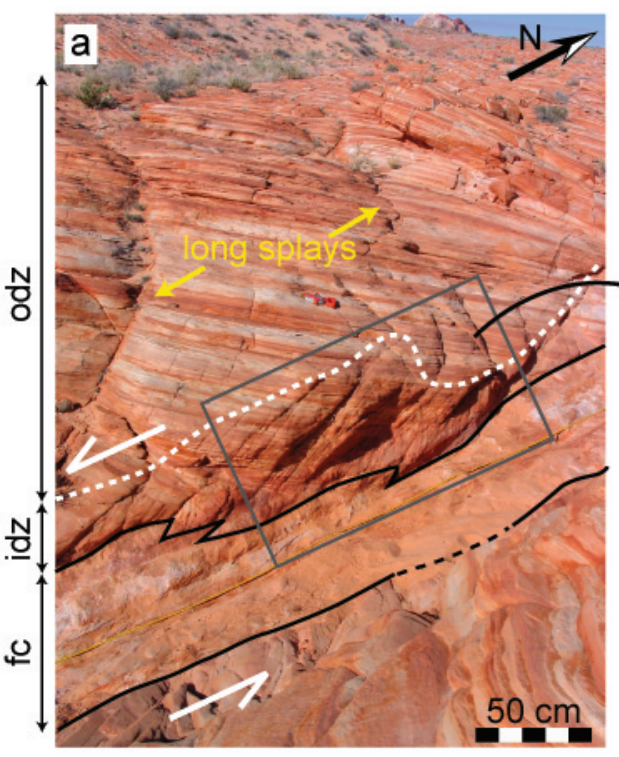

idz: inner damage zone odz: outer damage zone fc: fault core

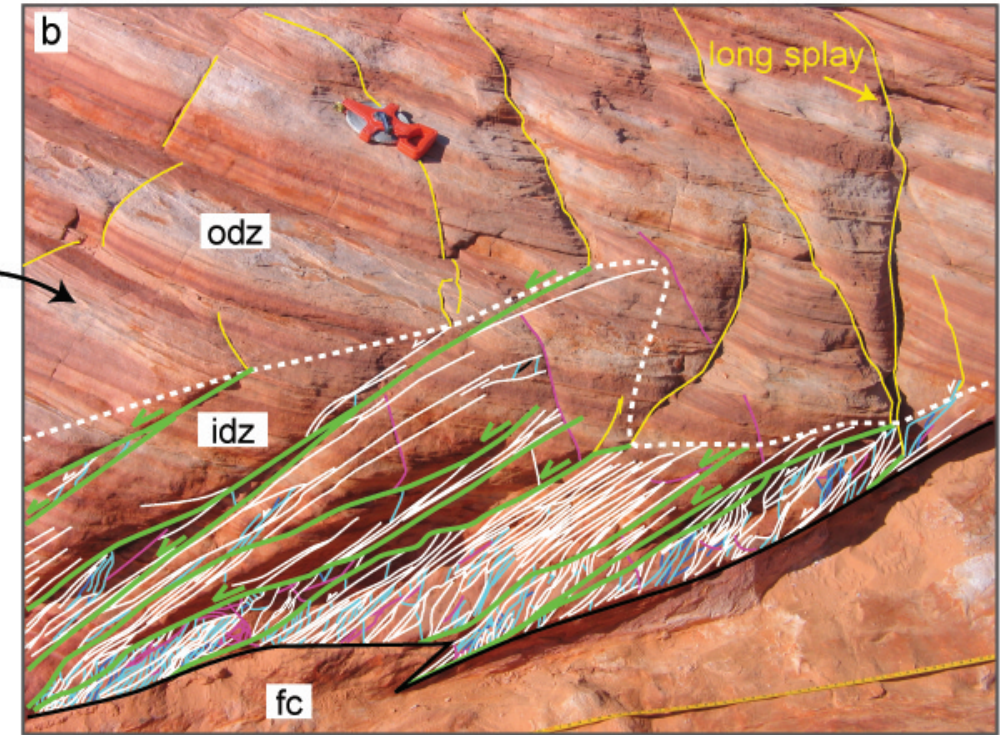

-initial en échelon joints first generation of splays second generation of splays
- third generation of splays fourth generation of splays - undifferenciated splays

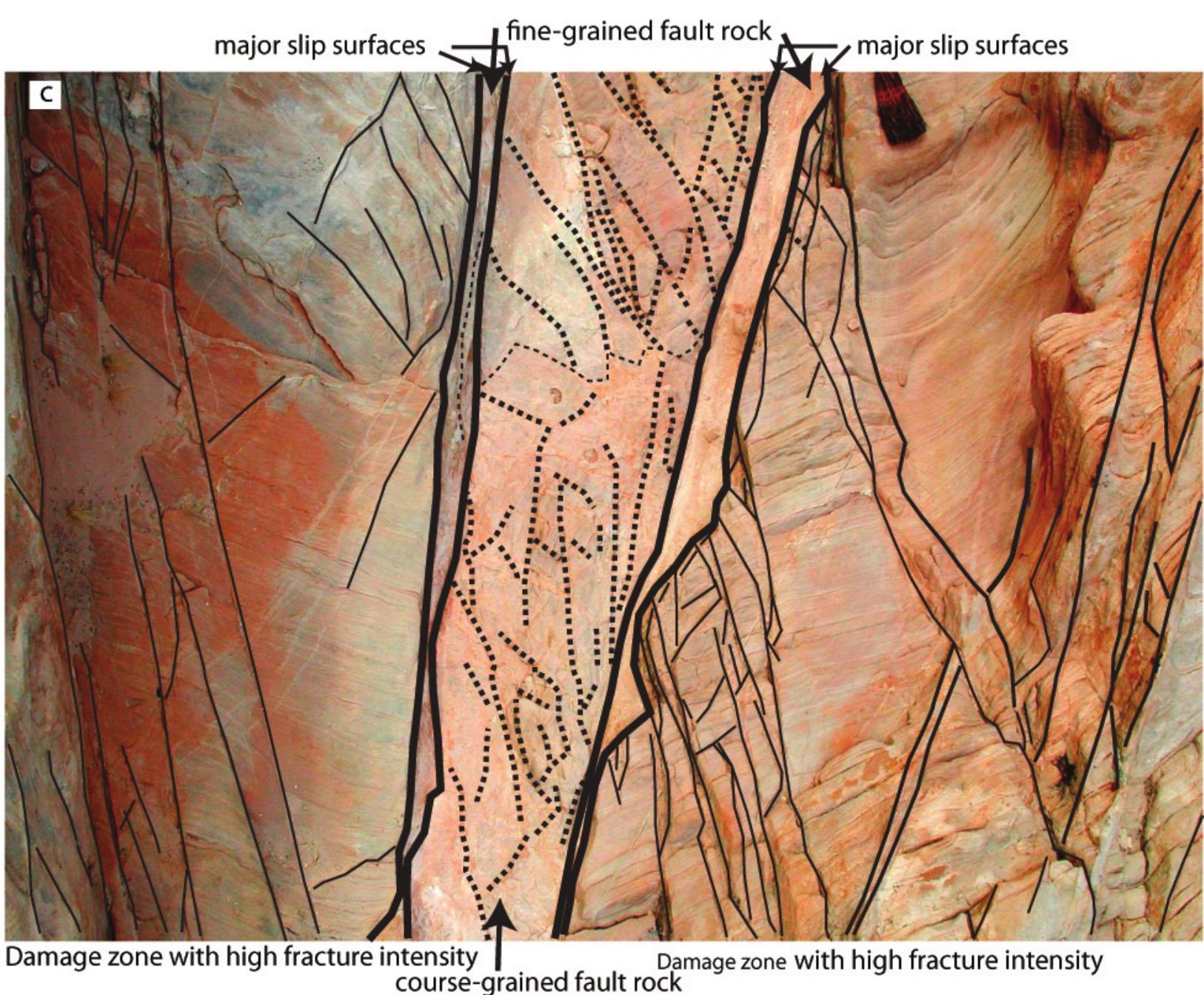


— initial en-echelon joints

_ first generation of splays

— second generation of splays

- third generation of splays fourth generation of splays fifth generation of splays

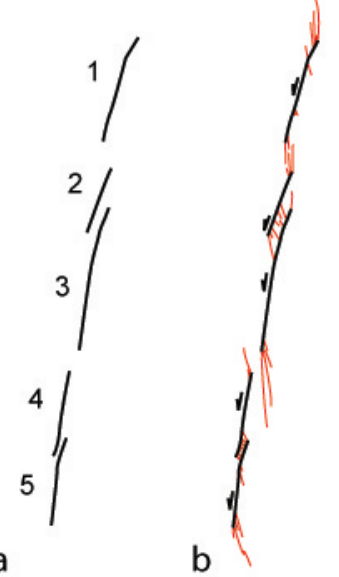

slip

$1 \mathrm{~cm}$ slip $1 \mathrm{~m}$

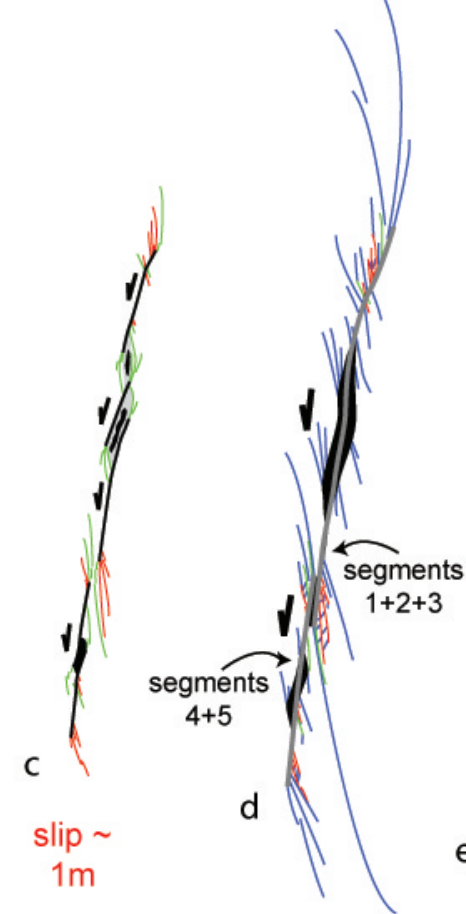

slip

$5 \mathrm{~m}$

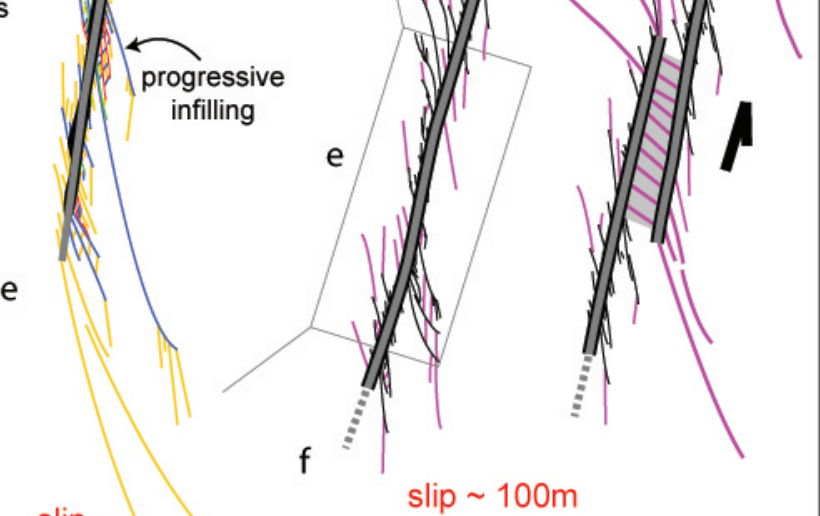

main slip surface

- fault core

intensely fractured zone

= idealized fault core and slip surfaces e slip

all segments linked:

through-going fault 
(b)

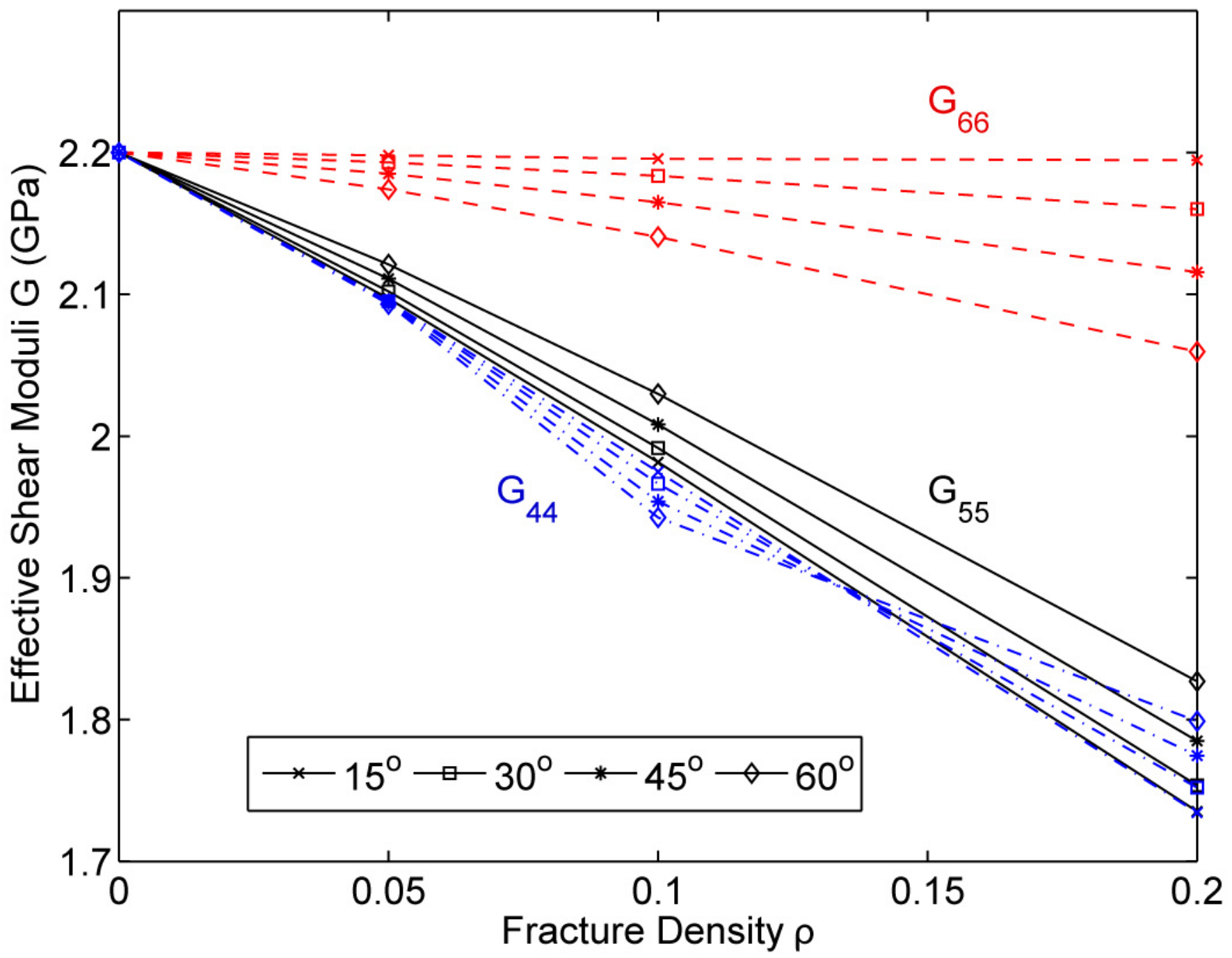


(c)

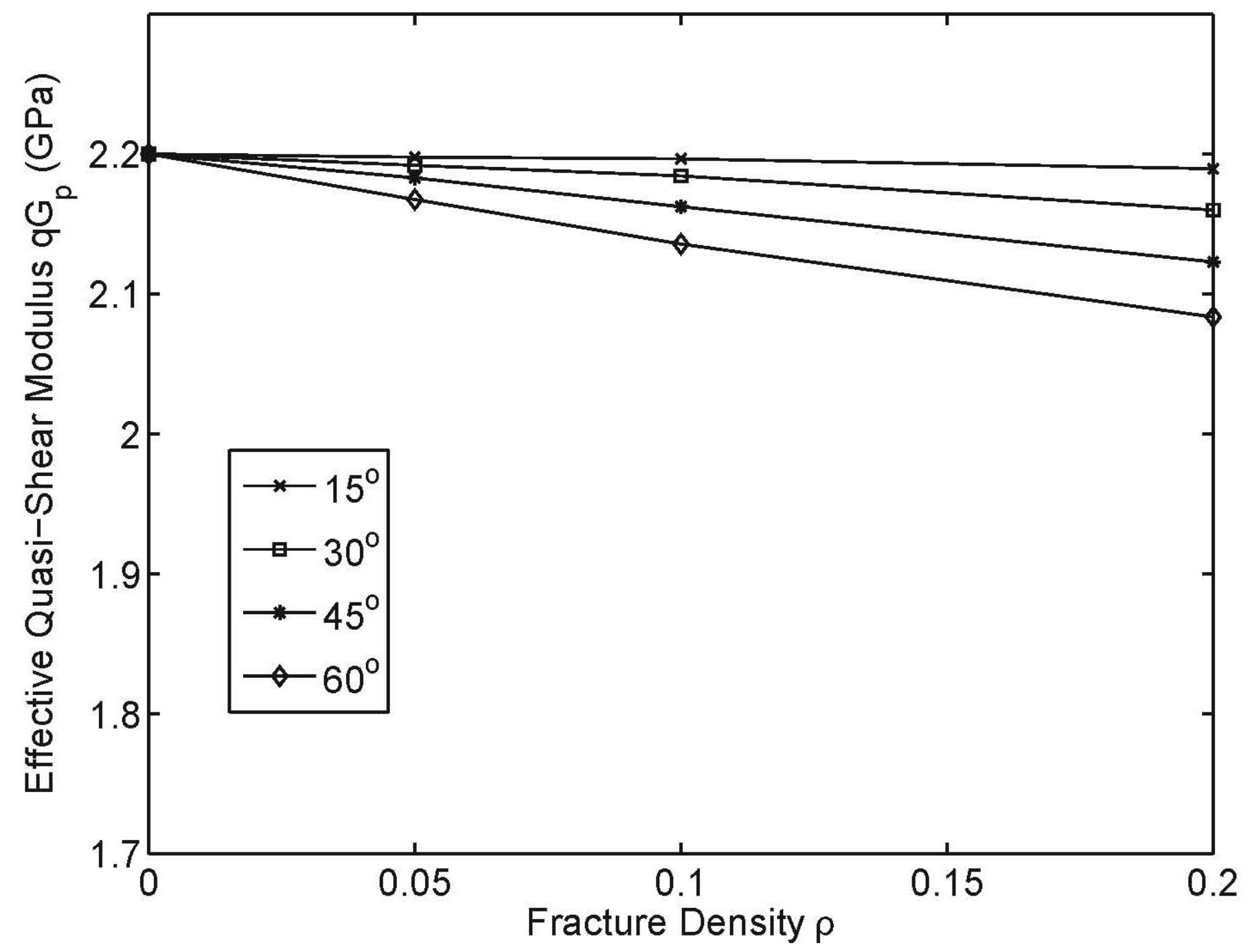

